\title{
Imbalance between Endothelial Damage and Repair: A Gateway to Cardiovascular Disease in Systemic Lupus Erythematosus
}

\author{
Anselm Mak ${ }^{1,2}$ and Nien Yee Kow ${ }^{2}$ \\ ${ }^{1}$ Division of Rheumatology, Department of Medicine, University Medicine Cluster, $1 E$ Kent Ridge Road, Level 10, \\ NUHS Tower Block, Singapore 119228 \\ ${ }^{2}$ Department of Medicine, Yong Loo Lin School of Medicine, National University of Singapore, Singapore 119228
}

Correspondence should be addressed to Anselm Mak; anselm_mak@nuhs.edu.sg

Received 20 January 2014; Accepted 21 February 2014; Published 26 March 2014

Academic Editor: Miguel A. González-Gay

Copyright ( 2014 A. Mak and N. Y. Kow. This is an open access article distributed under the Creative Commons Attribution License, which permits unrestricted use, distribution, and reproduction in any medium, provided the original work is properly cited.

\begin{abstract}
Atherosclerosis is accelerated in patients with systemic lupus erythematosus (SLE) and it leads to excessive cardiovascular complications in these patients. Despite the improved awareness of cardiovascular disease and advent of clinical diagnostics, the process of atherogenesis in most patients remains clinically silent until symptoms and signs of cardiovascular complications develop. As evidence has demonstrated that vascular damage is already occurring before clinically overt cardiovascular disease develops in lupus patients, intervention at the preclinical stage of atherogenesis would be plausible. Indeed, endothelial dysfunction, one of the earliest steps of atherogenesis, has been demonstrated to occur in lupus patients even when they are naïve for cardiovascular disease. Currently known "endothelium-toxic" factors including type 1 interferon, proinflammatory cytokines, inflammatory cells, immune complexes, costimulatory molecules, neutrophils extracellular traps, lupus-related autoantibodies, oxidative stress, and dyslipidemia, coupled with the aberrant functions of the endothelial progenitor cells (EPC) which are crucial to vascular repair, likely tip the balance towards endothelial dysfunction and propensity to develop cardiovascular disease in lupus patients. In this review, altered physiology of the endothelium, factors leading to perturbed vascular repair contributed by lupus EPC and the impact of proatherogenic factors on the endothelium which potentially lead to atherosclerosis in lupus patients will be discussed.
\end{abstract}

\section{Introduction}

1.1. Systemic Lupus Erythematosus and Cardiovascular Disease. Systemic lupus erythematosus (SLE) is a systemic autoimmune condition mainly mediated by immune-complex induced inflammation which potentially affects any organ system during the course of the disease [1]. Although the overall survival of lupus patients has been improving in the past 5 decades, excessive mortality is unanimously evident [2]. While disease- and treatment-related complications such as renal disease and infections remain as the leading causes of death in patients with SLE, cardiovascular disease (CVD) is emerging as an increasingly common cause of mortality amongst these patients over the past 30 years [3]. While patients with SLE in general are over 2 times more likely to have CVD as compared with the general populations [4], an epidemiological study revealed that lupus patients older than the age of 35 are $>50$ times more likely to develop CVD than their age- and sex-matched healthy counterparts [5]. The reasons for the high prevalence of CVD in lupus patients are multifactorial. Besides the fact that patients with SLE carry more unfavourable traditional Framingham risk factors such as hypertension, dyslipidaemia, and diabetes mellitus than their healthy counterparts, nonclassical cardiovascular risk factors, systemic inflammation and proinflammatory adipokines, and treatment-related side effects are operant [6]. While not as extensively studied as in patients with rheumatoid arthritis in larger scale studies [7-10], genetic polymorphisms potentially contributing to cardiovascular disease in patients with SLE have increasingly been identified in a number of lupus cohorts [11-16]. Thus far, genetic polymorphisms associated with premature atherosclerosis and cardiovascular disease in patients with SLE have been convincingly found in the interferon regulatory factor 8 (IRF8) 
[11], matrix metalloproteinase-2 (MMP-2) functional promoter [12], plasminogen activator inhibitor 1 (PAI-1) promoter [13], mannose-binding lectin-2 (MBL-2) [14], stromelysin promoter [15], and C-reactive protein (CRP) genes [16]. With the everincreasing knowledge in the pathogenesis of atherogenesis in SLE, more genetic polymorphisms related to CVD in patients with SLE are expected to be identified.

1.2. Early Recognition of Atherogenesis in Patients with Systemic Lupus Erythematosus. Currently, therapeutic strategy for CVD is considered "palliative" in that drugs such as antiplatelet agents, anticoagulants, antihypertensives, and statins aim to mitigate cardiovascular risk factors and reduce the probability of future cardiovascular events [17]. In the era of preventive medicine, it is prudent to recognize atherosclerosis early in its progress so that more meticulous monitoring can be instituted and potential primary interventions can be tested, with an ultimate aim to prevent the development of clinically overt cardiovascular complications such as arrhythmias, myocardial ischaemia, and subendocardial and even full-thickness myocardial infarctions. To date, a number of modalities to detect early changes in the process of atherogenesis such as carotid intima-media thickness [18-20], coronary calcium [21-23], speckle-tracking strain echocardiogram [24, 25], and endothelium-dependent vasodilation [26-30] have been reported in patients with SLE and related autoimmune disorders such as scleroderma and systemic vasculitides [1825]. Amongst these modalities, assessment of the endothelium has received much attention because, at present, it is strongly believed that endothelial dysfunction is one of the earliest steps involved in the process of atherogenesis [31]. Additionally, endothelial dysfunction is theoretically reversible, making it a potentially attractive site of target for preventive intervention against the development of CVD [32]. In this review, how various factors affect the physiology of the endothelium which result in the imbalance between endothelial damage and endothelial repair that lead to CVD, as evident in both murine lupus models and human disease, will be discussed. Information constituting this review was extracted from relevant original papers and review articles on PubMed between 1950 and January 2014 by using the combinations of the keywords "lupus," "cardiovascular," and "endothelial." Bibliography of the relevant articles obtained was thoroughly assessed for relevancy. References which were deemed to be relevant by the authors of this review were further hand-searched, with the useful information extracted for discussion in this paper.

\section{Normal Physiology of the Endothelium and the Functions of Nitric Oxide-In Brief}

The vascular endothelium is a monolayer of cells, which line the luminal surface of blood vessels of all sizes, and confers a physical barrier from potential injuries induced by various vascular toxic components in the blood such as inflammatory mediators, oxidizers, infective agents, and migrating inflammatory cells [33]. Aside from being a physical barrier, the endothelium regulates the vascular tone in response to physiological changes such as intravascular shear stress and high perfusion pressure by producing endothelium-derived relaxing factors (EDRF) which provokes vasodilation and reduces vascular resistance [34]. The EDRF was subsequently identified to be endothelial nitric oxide (NO), which is converted from the substrate L-arginine by the enzymatic action of endothelial NO synthase (eNOS) [35]. NO diffuses into the vascular smooth muscle layer and mediates cyclic GMP-mediated vasodilation. As involved in one of the earliest steps of atherogenesis, the deficiency in the production and bioavailability of $\mathrm{NO}$ as a result of endothelial damage lead to impairment of endothelial-dependent vasodilation, which has been proven to be an independent risk factor of cardiovascular events [36, 37].

Besides regulation of vascular tone, $\mathrm{NO}$ also contributes to part of the anti-inflammatory and antithrombotic properties on the endothelial level. NO has been demonstrated to reduce interleukin (IL)-1-induced VCAM-1 expression which is paralleled by the reduction of monocyte adhesion to the endothelium, in addition to repressing the production of soluble IL-6 and IL-8 $[38,39]$. Recently, an in vitro study found that AMP-activated protein kinase, which is central to the regulation of eNOS, reduced TNF $\alpha$-induced monocyte adhesion on human aortic endothelial cells and endothelial MCP-1 expression [40]. As for the antithrombotic effect of $\mathrm{NO}$, it has been demonstrated that the activity of eNOS and the endothelial isoform of NO are critical regulators which suppress platelet activation and aggregation [41].

\section{Assessment of Endothelial Function: The Current State}

3.1. Endothelium-Dependent and Endothelium-Independent Flow-Mediated Dilation. To date, there are two established methods to assess the function of the endothelium biophysically, namely, the endothelium-dependent vasodilation, or flow-mediated vasodilation (FMD), and endothelium-independent vasodilation [42]. In brief, for measuring the FMD, subjects are asked to rest in supine position for at least ten minutes before the measurement in the same position. FMD at the brachial artery is measured using a high-resolution ultrasound system, in which the ultrasound probe is steadied by a stereotactic holding device which also permits fine positional adjustment. Reactive hyperaemia is induced by rapid inflation of a pneumatic cuff placed around the proximal forearm to pressure $50 \mathrm{~mm} \mathrm{Hg}$ above the systolic blood pressure for around 5 minutes, followed by rapid deflation [42]. Change of the vessel diameter at maximum dilatation and percentage of FMD change can hence be detected by the ultrasound probe and calculated by a computer program, with the peak reactive hyperaemic blood flow at 45 to 60 seconds after cuff deflation [42]. All FMD studies are preferably performed after abstention from food and exercise, for 8 to 12 hours, and caffeine and alcohol for 24 and 48 hours, respectively [42]. Another established way to assess endothelial reactivity is to measure endothelium-independent vasodilation of the brachial artery before and after administration of nitroglycerin, which is a direct smooth-muscle relaxant without the need for nitric oxide production and release by the endothelium. After 10 to 15 minutes of rest 
following completion of endothelium-dependent FMD measurement, $0.4 \mathrm{mg}$ of nitroglycerin, in the form of sublingual spray or tablet, is administered. Peak vasodilation occurs between 3 and 5 minutes after nitroglycerin administration and endothelium-independent FMD can be measured, using the same method as for endothelium-dependent FMD, except that no forearm occlusion is required [43]. According to a recent meta-analysis of 13 studies, FMD but not endotheliumindependent vasodilation, is reduced in patients with SLE. However, interpretation of FMD needs to be cautious especially in lupus patients of advanced age and in those who have longstanding SLE because these factors independently affect endothelial function [43].

3.2. Endothelial Progenitor Cells. Originated from the haematopoietic stem cells, the endothelial progenitor cells (EPC) are believed to participate in repairing the damaged endothelium and maintaining the integrity of vascular lining [44]. In a number of well-conducted case-control studies, EPC have been shown to be reduced in patients carrying traditional cardiovascular risk factors such as diabetes mellitus and hypertension $[45,46]$, as well as in those with clinical cerebrovascular and cardiovascular diseases [47, 48]. In a 1year prospective study of 519 patients with angiographyconfirmed coronary artery disease, patients with higher baseline levels of EPC (identified as CD34+CD133+CD309+ cells) were noted to be associated with reductions in risks of death from cardiovascular causes, a first major cardiovascular event, revascularization procedure, and hospitalization by $69 \%, 26 \%, 23 \%$, and $38 \%$, respectively, than those with lower baseline EPC levels, after adjusting for age, sex, and vascular risk factors [49].

In rheumatic disorders, EPC have been relatively well studied in scleroderma and SLE, but results are inconsistent [50-54]. The main problem of EPC studies likely stems from the absence of a consensus on the surface markers leading to identification of the true population of EPC, as well as a validated and reliable strategy to identify them. In fact, the European League Against Rheumatism (EULAR) Scleroderma Trials and Research group (EULAR/EUSTAR) has recently proposed a standard method in identifying EPC in patients with scleroderma by the use of fluorospheres and elimination of dead cells and lineage-positive population [51]. Such method resulted in a consistent finding of low levels of circulating EPC in patients with scleroderma [51]. In SLE, while most of the studies demonstrated lower circulating EPC in patients with SLE than their healthy counterparts, results are inconsistent, most likely due to different protocols adopted for identifying EPC [52-54]. Nevertheless, whether the number of circulating EPC can predict cardiovascular events in patients with SLE remains to be answered by prospective studies.

\section{Altered Physiology of Endothelium in SLE}

4.1. Factors Associated with Endothelial Damage. Being the hallmark of the pathogenesis of SLE, inflammation has been postulated to be one of the most important triggers of endothelial damage. Type 1 interferon (IFN) appears to play the critical role in mediating endothelial damage in patients with SLE [55], alongside with other endothelial toxic mediators and conditions both dependent and independent of type 1 IFN including proinflammatory cytokines, costimulatory molecules, immune complexes, oxidized lipid species, oxidative stress, autoantibodies, including antiphospholipid antibodies and anti-annexin- $\mathrm{V}$ antibodies, and the process of neutrophil extracellular traps ("Netosis").

4.2. Type 1 Interferon. Type 1 IFN, which is central to the pathogenesis of SLE and mainly produced by the plasmacytoid dendritic cells ( $\mathrm{pDC}$ ), is increased in the majority of patients with SLE $[56,57]$. pDC residing in atherosclerotic plaques produce type I IFN which locally induces adjacent CD4+ T cells to express TNF-related apoptosisinducing ligand (TRAIL) [58]. While TRAIL was demonstrated to be antiatherosclerotic in the context of chronic inflammation and deficiency of TRAIL was shown to be associated with calcification in atherosclerosis in a mouse model $[59,60]$, TRAIL potentially leads to plaque rupture and acute coronary event [58]. Type 1 IFN also induces myeloid dendritic cells (mDCs) in atherosclerotic plaques to produce inflammatory cytokines and matrix metalloproteinases which are capable of destabilizing plaques [61]. Platelet aggregation and thrombosis are also induced by type 1 IFN on diseased endothelium in a P-selectin-dependent fashion [62]. Indeed, SLE platelets have been demonstrated to have heightened IFN signatures which are able to activate pDC and subsequent IFN $\alpha$ production through the interaction between CD40 and CD40L, potentially perpetuating endothelial toxicity and vascular thrombosis by further activating platelet aggregation as a positive feedback loop [63].

IFN $\alpha$ has recently been shown to affect vasculogenesis by interfering the phenotypes and function of EPC [64]. How IFN $\alpha$ affects EPC and impairs endothelial repair will be discussed in subsequent sections.

\subsection{Oxidized Low-Density Lipoproteins and Proinflammatory} High-Density Lipoproteins. While epidemiological studies have demonstrated strong associations between high serum levels of circulating oxidized low-density lipoproteins (oxLDL) and coronary artery disease in the general population $[65,66]$, a similar association appears to hold true for patients with SLE especially in those with cardiovascular disease and antiphospholipid antibody (APA) syndrome (APS). [67-69]. Mechanistically, ox-LDL induces the secretion of chemokines and proinflammatory cytokines such as monocyte chemotactic protein-1 (MCP-1), IL-8, and IL-6 from the endothelial cells [70]. As a consequence, T cells, monocytes, and dendritic cells are attracted to the subendothelial space of the diseased endothelium where monocytes further differentiate into macrophages that constitute the foam cells under the further stimulation of the ox-LDL [71]. Macrophages, under the influence of IFN $\gamma$ from the T cells, express key proinflammatory cytokines including TNF $\alpha$ and IL-1 which in turn aggravate the expression of adhesion molecules on the endothelium including vascular cell adhesion molecule 
1 (VCAM-1), intercellular adhesion molecule 1 (ICAM1), and E-selectin and further attracts monocytes [72]. Additionally, ox-LDL binds to CD14 of macrophages and leads to inhibition of their abilities to phagocytose and induction of CD36 expression [73]. Acting as a scavenger receptor on macrophages, activation of CD36 enhances the uptake of ox-LDL and upregulates the NF- $\kappa \mathrm{B}$ expression, perpetuating local inflammatory response [73]. Interestingly, while HDL has long been advocated as the "good cholesterol" in that its level is inversely associated with cardiovascular disease and it functions to reverse LDL and phospholipid oxidation through apolipoprotein (apo A-1) and paraoxonase, respectively, the functions of HDL which can be either anti-inflammatory or inflammatory, is more pathologically relevant in atherogenesis [74]. The proinflammatory form of HDL, which is increased in acute-phase response, has been demonstrated to be able to impair LDL oxidation and the level of proinflammatory HDL was found to be significantly associated with ox-LDL levels in patients with SLE [75].

4.3.1. Atherogenic Adipokines. Amongst various atherogenic adipokines, leptin has been most extensively and systematically studied in patient with SLE, in relation to premature atherosclerosis and cardiovascular disease [76-82]. Leptin is an adipocyte-derived protein which regulates appetite, and energy intake and its expenditure [76]. Plasma leptin was shown to be increased in obese individuals and was correlated with serum C-reactive protein level, endothelial dysfunction, and cardiovascular event $[77,78]$. Serum leptin levels have been demonstrated to be higher in patients with SLE as compared with those of healthy individuals $[79,80]$. Recently, high serum level of leptin of $\geq 34 \mathrm{ng} / \mathrm{dL}$ has been shown to be associated significantly with carotid plaques with an odds ratio of 7.3 in a study of 210 female patients with SLE and 100 age-matched healthy controls [79]. In the NZB/W F1 mouse model, leptin was shown to enhance survival and proliferation of autoreactive $\mathrm{T}$ cells [81] and promote Th17 response through the transcription of Retinoid-Acid Receptor-related Orphan Receptor gamma $t(R O R \gamma t)$ in $\mathrm{CD} 4+\mathrm{T}$ cells [82]. While further information is required, these findings imply that targeting at leptin would be a potential strategy to combat cardiovascular disease in patients with SLE.

4.4. Oxidative Stress. Chronic inflammation of SLE leads to oxidative stress with the production of reactive oxygen species and accumulation of advanced glycation end products which are detrimental to the wellbeing of the endothelium [83]. Recently, it has been demonstrated that under the influence of IFN $\alpha$, cultured lymphocytes undergo intracellular formation of the tubuloreticular structures (TRS) which signifies the presence of oxidative stress on the intracellular level. Additionally, the presence of TRS is significantly and proportionally elevated in higher disease activity of SLE [84]. Thus, it may potentially explain why a number of studies has demonstrated significant associations between clinical disease activity of SLE and various biomarkers of oxidative stress [85-87].

\subsection{Costimulatory Molecules}

4.5.1. CD137-CD137L. CD137 (4-1BB) belongs to the TNF superfamily which is mainly expressed on activated $\mathrm{T}$ cells and natural killer T cells. Its ligand, CD137L, is constitutively expressed on antigen presenting cells (APC) including B cells and dendritic cells (DC) $[88,89]$. CD137 is a potent costimulatory receptor molecule and its cognate interaction with CD137L induces proliferation of activated T cells, and profound immunoglobulin production in B cells as well as maturation of DC on which CD137L is expressed [89]. Interestingly, agonizing CD137 with anti-CD137 monoclonal antibodies alleviates glomerulonephritis and improves mortality in MRL/lpr mice alongside with reduction of anti-dsDNA antibody, CD4+ T cells, and germinal centre formation [90]. In NZW/B mouse model, agonizing CD137 leads to the alleviation of lupus-like manifestations by increasing splenic CD4+CD25+ T regulatory cells [91].

Endothelial cells have also been shown to express CD137 upon activation and stimulation by proinflammatory stimuli such as TNF $\alpha$ [92]. The interaction between CD137 on the endothelium and CD137L expressed on monocytes enhances the former to express adhesion molecules such as ICAM1 and VCAM-1, and the latter to migrate to vascular wall in an E-selectin and ICAM-1-dependent fashion [92-94]. Thus, CD137 activation promotes atherosclerosis early on the endothelium level. Although agonistic anti-CD137 antibody demonstrates alleviation of lupus in animal models [90, 91], its potential to cause atherosclerosis may be a relevant concern if this monoclonal antibody is to be evaluated in clinical trials for the treatment of SLE.

4.5.2. CD40-CD40L. Similar to CD137L, CD40L belongs to the TNF superfamily and is expressed on T cells $[95,96]$. The CD40L gene is a SLE susceptible gene which is overexpressed in female lupus patients, partly due to the consequence of demethylation of the regulatory sequence on the inactivated $\mathrm{X}$ chromosome of $\mathrm{T}$ cells $[95,96]$. CD40L and CD40 interaction between $\mathrm{T}$ cells and CD40-expressing endothelial cells triggers endothelial expression of adhesion molecules such as VCAM-1 [97]. While antagonizing CD40L with anti-CD40L in LDL-receptor deficient mice has been shown to cause substantial reductions of atherosclerotic lesions and their lipid content, and the amount of intralesional macrophages and T cells, as well as VCAM-1 expression on the endothelium [98], a clinical trial testing anti-CD40L in patients with SLE was unfortunately terminated prematurely due to excessive occurrence of cardiovascular events [99]. Thus, it seems unlikely that anti-CD40L will be able to protect the cardiovascular system in human SLE even though promising results in alleviating lupus nephritis was evident [99].

4.6. Proinflammatory Cytokines. Key proinflammatory cytokines which have been advocated to play a role in endothelial damage include IL-17, IFN-gamma (IFN $\gamma$ ), and TNF $\alpha$. Expansion of the Th17 population and elevation of serum IL-17 levels have been clearly demonstrated in patients with SLE [100]. In nonlupus models, IL-17 has been implicated in the development of atherosclerotic plaques. Indeed, depleting 
IL-17R by knocking out the IL-17R gene of LDL receptordeficient atherosclerosis-prone mice reduced the size of aortic atherosclerotic plaques in these mice fed with Western-type diet [101]. In humans, $\mathrm{T}$ cells which produce both IL-17 and IFN $\gamma$ were demonstrated to reside in the specimens of atherosclerotic plaque from patients with coronary heart disease [102]. Furthermore, in patients with acute coronary syndrome, higher number of circulating Th17 cells and levels of IL-17 as well as its related cytokines such as IL-6 and IL23 levels were demonstrated as compared with those with stable angina and healthy individuals [102]. Nevertheless, data addressing whether IL-17 is directly related to clinical cardiovascular events are sparse.

As far as TNF $\alpha$ is concerned, our team has recently demonstrated that TNF $\alpha$ is elevated in patients with SLE with the use of the multiplex immunoassay platform, as compared with age- and sex-matched healthy individuals [103]. TNF $\alpha$ elevation was shown to be associated with higher coronary calcium scores in patients with SLE [104]. TNF $\alpha$ induces adhesion molecules expression on, and enhances the recruitment of $\mathrm{T}$ cells and monocytes to the endothelial cells [105]. As for IFN $\gamma$ which has been discussed above, it is expressed by activated $\mathrm{T}$ cells and other immunocytes and it induces the macrophages to express TNF $\alpha$ and IL-1 which in turn aggravate the expression of VCAM-1, ICAM-1, and Eselectin and further attracts monocytes towards the diseased endothelium [72]. After all, IFN $\gamma$ per se promotes oxidative stress and resultant endothelial damage [83].

4.7. Autoantibodies against ox-LDL, Phospholipids, and Annexin-V in Systemic Lupus Erythematosus. By intuition, antibodies against ox-LDL may alleviate the toxic effect of oxLDL on the endothelium. Indeed, animal studies revealed that infusion of anti-LDL protected against atherosclerosis in hypercholesterolemic mice [106] and immunization of modified LDL, which triggered high titre of anti-ox-LDL antibodies, reduced atherosclerotic lesions in LDL-receptor deficit rabbits [107]. However, the results do not appear to be translated to human disease. While the cross-reactivity between antibodies against cardiolipin (a phospholipid species) and ox-LDL might imply an increased chance of the development of CVD in patients with SLE, the association between antiox-LDL antibodies and CVD remains inconsistent in these patients $[67,108,109]$. On the other hand, the association between antiphospholipid antibodies and CVD is undoubtedly clear. Formation of immune complexes involving $\beta 2$ glycoprotein 1 has been shown to be detrimental to the vascular wall in part due to the stimulation of adhesion molecule expressions on the endothelium [110].

Annexin-V is a naturally occurring and potent phospholipid-binding anticoagulant protein which protects the endothelium from damage by inhibiting the procoagulant effects of tissue factors and binding to negatively charged phospholipids [111, 112]. In patients with SLE, besides the higher levels of anti-annexin- $\mathrm{V}$ antibodies, serum anti-annexin- $\mathrm{V}$ levels were shown to be predictive of poorer endothelial function gauged by endothelium-dependent vasodilation [111113]. Mechanistically, it is evident that the binding of the atheroprotective annexin- $\mathrm{V}$ to phospholipid bilayer of the endothelium is interfered by the anti- $\beta 2$-glycoprotein 1 antibodies [114].

4.8. Immune Complexes. Autoantibodies, which are characteristically abundant in SLE, form immune complexes (IC) with their respective autoantigens. Complements are subsequently fixed onto the IC in an attempt to be opsonised for removal by phagocytes. In fact, complement-associated immune complexes induce endothelial expression of adhesion molecules which enhance migration of $\mathrm{T}$ cells and monocytes towards the subendothelial space that initiate endothelial damage [115]. Interestingly, not all IC are detrimental to the wellbeing of the endothelium. Clq complexes are indeed atheroprotective in that they are able to trigger clearance of oxLDL by macrophages [116]. Thus, qualitative and quantitative deficiency of $\mathrm{Clq}$ found in patients with SLE may be implicated as a risk factor for CVD.

4.9. Neutrophil Extracellular Traps. A recent breakthrough in the research of antimicrobial mechanism by neutrophils is the discovery of the formation of neutrophil extracellular traps (NETs) [117]. NETs essentially comprise intracellular antimicrobial proteins such as LL37 and human neutrophils peptide and DNA which are microbicidal. In patients with SLE, the presence of antibodies against ribonucleoproteins and those against LL37 prime and increase the propensity of NET formation when compared to healthy individuals [118]. In addition, NETs confer strong cytotoxic signals which lead to endothelial damage and endothelial apoptosis [119]. Furthermore, NETs have been shown to activate platelets which induce thrombosis at the site of vascular injury and induce IFN $\alpha$ production by $\mathrm{pDC}$ which are activated by NETs-stimulated lupus neutrophils [120]. As a result, the tendency of NET formation in patients with SLE results in direct endothelial apoptosis and damage which are further potentiated by its effects on platelet and pDC activation, enhancing vascular thrombosis and perpetuation of the vicious cycle of endothelial dysfunction.

\subsection{Factors Associated with Perturbed Vascular Repair}

4.10.1. Endothelial Progenitor Cells. The serum levels of IFN $\alpha$, and transcription of genes which enhance the expression of those encoding IFN $\alpha$ ("IFN signatures"), are upregulated in patients with SLE. IFN $\alpha$ plays a central role in the pathogenesis of SLE and, at the same time, it is "toxic" to the endothelium [121]. For example, EPC were demonstrated to undergo striking apoptosis after treating with IFN $\alpha$, accompanied by a reduced capability to differentiate into mature endothelial cells, which were reversible by neutralizing IFN $\alpha$ [122]. It has been postulated that type 1 IFN leads to perturbed vascular repair by repressing the expression of angiogenic factors such as VEGF and IL-1 $\beta$ on the endothelium, coupled with enhanced expression of IL-18 [123]. Very recently, angiogenic $\mathrm{T}$ cells (Tang), a novel subset of $\mathrm{T}$ cells which are functionally similar to the EPC in terms of the ability of endothelial repair, have been described in patients with rheumatoid arthritis [124]. Tang express CD3, CD31, and CD184 and their number in the peripheral blood was found to be correlated with 
TABLE 1: A summary of the factors and their mechanisms which contribute to endothelial damage and impaired repair of the endothelium.

\begin{tabular}{ll}
\hline Endothelial damage & Description (ref) \\
\hline & Chiefly produced by pDC, IFN $\alpha$ is increased in SLE [46, 47] and it stimulates CD4+ \\
& cells residing in atherosclerotic plaque to express TRAIL which in turn enhances \\
plaque rupture [48]. & IFN $\alpha$ induces mDC residing in atherosclerotic plaques to express proinflammatory \\
Type 1 interferon & cytokines and MMPs which destabilize plaques and promote plaque rupture [49]. \\
& IFN $\alpha$ stimulates platelet aggregation and vascular thrombosis in a P-selectin \\
& dependent fashion [50]. \\
\hline & Type 2 IFN is produced by a wide range of immunocytes including mDC, activated \\
lymphocytes, and monocytes. It induces monocytes to upregulate IL-1 and TNF $\alpha$ & which induce the expression of adhesion molecules such as VCAM-1, E-selectin, \\
& and ICAM-1 on the endothelium [59]. \\
\hline
\end{tabular}

Major proinflammatory cytokines, including TNF $\alpha$, IL-1, IL-17, and IFN $\gamma$ which are elevated in SLE, stimulate endothelial expression of adhesion molecules and lead to

Proinflammatory cytokines recruitment of atherogenesis-enhancing monocytes and $\mathrm{T}$ cells to the subendothelial space $[59,85]$. A clinical study revealed that higher serum TNF $\alpha$ levels were associated with higher coronary calcium score [84], a radiological predictor of coronary artery event.

Immune complexes Complement-fixed immune complexes upregulate the expression of adhesion molecules on the endothelium [96] However, Clq-containing immune complexes are atheroprotective as they promote clearance of ox-LDL by macrophages [97].

Endothelium expresses CD137 upon activation by proinflammatory signals such as TNF $\alpha$ [72]. Ligation of endothelial CD137 with CD137L expressed on monocytes induces the former to express adhesion molecules and facilitate monocyte

Costimulatory molecules migration to the subendothelial space [72-74]. CD40 is expressed on the endothelium, and its interaction with CD40L expressed on T cells induces expression of VCAM-1 which enhances atherosclerosis [77]. A clinical study testing anti-CD40L was however terminated due to the unexpected excessive occurrence of cardiovascular events [79].

Oxidized lipids Circulating ox-LDL induces endothelial secretion of MCP-1, IL-8, and IL6 which attract DC, T cells, and monocytes. Monocytes are induced to form foam cells under the further influence of ox-LDL and proinflammatory cytokines [58].

Oxidative stress increases with higher disease activity of SLE [83]. Reactive oxygen

Oxidative stress species formed during oxidative stress lead to accumulation of glycation end products which are toxic to the endothelium [63].

Annexin- $\mathrm{V}$ is a naturally occurring phospholipid-binding anticoagulant protein. Lupus patients demonstrate elevation of the anti-annexin-V antibody, which is Autoantibodies related to inferior endothelial function [92-94]. Indeed, antiphospholipid antibodies, in particular the anti- $\beta 2$-glycoprotein- 1 antibodies, interferes the binding between the atheroprotective annexin- $\mathrm{V}$ to the phospholipid bilayer of the endothelium [95].

Antibodies against ribonucleoproteins and LL37 promote NET formation, which induces IFN $\alpha$ production by pDC as result of NETs-stimulated lupus neutrophils [99-101], NETs formation leads to activation of vascular thrombosis and endothelial apoptosis [99-101].

NETs Description (ref).

Perturbation of vascular repair

IFN $\alpha$ induces EPC apoptosis and the ability of EPC to differentiate to mature endothelium $[102,103]$. Vascular repair is impaired by the ability of IFN $\alpha$ to repress

Endothelial progenitor cells VEGF and IL-1 and upregulate IL-18 on the endothelium [104]. LDG is another source of IFN $\alpha$ apart from pDC which is elevated in patients with SLE. LDG impairs endothelial cell repair, and depletion of LDG restores the ability of EPC to differentiate into mature EPC and repair the endothelial monolayer [106].

ref: references; pDC: plasmacytoid dendritic cells; IFN $\alpha$ : interferon-alpha; SLE: systemic lupus erythematosus; TRAIL: TNF-related apoptosis-inducing ligand; mDC: myeloid dendritic cells; MMP: matrix metalloproteinases; IFN: interferon; IL: interleukin; TNF $\alpha$ : tumour necrosis factor-alpha; VCAM-1: vascular cell adhesion molecule 1; ICAM-1: intercellular adhesion molecule 1; IFN $\gamma$ : interferon-gamma; ox-LDL: oxidized low-density lipoproteins; MCP-1: monocyte chemotactic protein-1; DC: dendritic cells; NETs: neutrophil extracellular traps; LDG: low-density granulocytes. 
that of the EPC in patients with rheumatoid arthritis [124]. Interestingly, the number of circulating Tang was associated positively with the positivity of antinuclear antibody and serum IFN $\alpha$ level and negatively with the occurrence of cardiovascular events in 103 patients with rheumatoid arthritis [124]. Since positivity of antinuclear antigen, high IFN $\alpha$ level and propensity to develop cardiovascular disease are evident in patients with SLE, phenotypic and functional studies of Tang in lupus patients in relation to cardiovascular disease would potentially yield exciting information of translational potential.

In animal lupus models, NZW/B mice were shown to have impaired endothelium-dependent vasorelaxation, reduction in the quantity, and increase in apoptosis of bone marrow and splenic EPC as compared with BALB/c controls. In addition, EPC from NZW/B failed to differentiate into mature endothelial cells as what $\mathrm{C} 57 \mathrm{BL} / 6$ mice did. Type 1 IFN signatures were increased in EPC of NZW/B mice and IFN $\alpha$ was shown to induce apoptosis of EPC in vivo [125]. Interestingly, B6/lpr mice did not demonstrate quantitative, phenotypic, and functional abnormalities of EPC. While it gives researchers the information that B6/lpr mice might not be an ideal murine model to study endothelial physiology in lupus, lupus activity and renal dysfunction, which are more prominent in the B6/lpr mice, are not the sole contributors to endothelial dysfunction. Locally produced IFN $\alpha$ can induce uptake of ox-LDL into macrophages.

Besides the $\mathrm{pDC}$ which are the major producer of IFN $\alpha$ in patients with SLE, low-density granulocytes (LDGs), which are elevated in patients with SLE, have been demonstrated to produce type 1 interferon sufficiently enough to impair vascular repair [126]. In fact, depletion of LDGs instead of pDC in patients with SLE was shown to restore the capability of EPC to differentiate into normal endothelial monolayers [126].

\section{Conclusion}

Recognition of atherogenesis early in the pathogenesis taking place in the endothelium, exploration of the value of FMD and circulating EPC, and research for potential intervention to maintain the wellbeing of the endothelium before clinical cardiovascular disease develops are potentially useful and highly relevant in reducing cardiovascular mortality and morbidity. Type 1 IFN, which is important to the pathogenesis of SLE, appears to be crucial in initiating and perpetuating endothelial damage and impairing vascular repair through its inhibitory action in EPC. Supported by a prevalent study that high IFN signature is associated with endothelial dysfunction, high coronary calcium score and carotid IMT after controlling for traditional cardiovascular risk factors [127], suppression of type 1 IFN in selected patients with heightened IFN signature might therefore be an attractive avenue in preventing cardiovascular disease in patients with SLE. However, stronger evidence from prospective studies which advocates the association between heavy IFN signatures and development of cardiovascular disease amongst lupus patients is undoubtedly required. In addition, much more work needs to be done to further obtain and validate available knowledge in order to translate it into potentially beneficial therapeutic and preventive interventions against cardiovascular disease in patients with SLE. Table 1 summarizes the factors and their potential mechanisms which contribute to endothelial damage and impaired endothelial repair in SLE.

\section{Conflict of Interests}

The authors declare that there is no conflict of interests regarding the publication of this paper.

\section{References}

[1] M. Wahren-Herlenius and T. Dörner, "Immunopathogenic mechanisms of systemic autoimmune disease," The Lancet, vol. 382, no. 9894, pp. 819-831, 2013.

[2] A. Mak, M. W. Cheung, H. J. Chiew, Y. Liu, and R. C. Ho, "Global trend of survival and damage of systemic lupus erythematosus: meta-analysis and meta-regression of observational studies from the 1950s to 2000s," Seminars in Arthritis and Rheumatism, vol. 41, no. 6, pp. 830-839, 2012.

[3] S. Bernatsky, J. F. Boivin, L. Joseph et al., "Mortality in systemic lupus erythematosus," Arthritis and Rheumatism, vol. 54, no. 8, pp. 2550-2557, 2006.

[4] A. E. Hak, E. W. Karlson, D. Feskanich, M. J. Stampfer, and K. H. Costenbader, "Systemic lupus erythematosus and the risk of cardiovascular disease: results from the nurses' health study," Arthritis Care and Research, vol. 61, no. 10, pp. 1396-1402, 2009.

[5] S. Manzi, E. N. Meilahn, J. E. Rairie et al., "Age-specific incidence rates of myocardial infarction and angina in women with systemic lupus erythematosus: comparison with the Framingham study," The American Journal of Epidemiology, vol. 145, no. 5, pp. 408-415, 1997.

[6] J. Bäck, C. Lood, A. A. Bengtsson, K. N. Ekdahl, and B. Nilsson, "Contact activation products are new potential biomarkers to evaluate the risk of thrombotic events in systemic lupus erythematosus," Arthritis Research and Therapy, vol. 15, no. 6, article R206, 2013.

[7] R. López-Mejías, M. García-Bermúdez, C. González-Juanatey et al., "NFKB1-94ATTG ins/del polymorphism (rs28362491) is associated with cardiovascular disease in patients with rheumatoid arthritis," Atherosclerosis, vol. 224, no. 2, pp. 426-429, 2012.

[8] R. López-Mejías, F. Genre, M. García-Bermúdez et al., “The 11q23.3 genomic region-rs964184-is associated with cardiovascular disease in patients with rheumatoid arthritis," Tissue Antigens, vol. 82, no. 5, pp. 344-347, 2013.

[9] R. López-Mejías, C. González-Juanatey, M. García-Bermúdez et al., "The lp13.3 genomic region-rs599839-is associated with endothelial dysfunction in patients with rheumatoid arthritis," Arthritis Research and Therapy, vol. 14, no. 2, article R42, 2012.

[10] R. López-Mejías, F. Genre, M. García-Bermúdez et al., "The $\mathrm{ZC} 3 \mathrm{HCl}$ rs11556924 polymorphism is associated with increased carotid intima-media thickness in patients with rheumatoid arthritis," Arthritis Research and Therapy, vol. 15, no. 5, article R152, 2013.

[11] D. Leonard, E. Svenungsson, J. K. Sandling et al., "Coronary heart disease in systemic lupus erythematosus is associated with interferon regulatory factor-8 gene variants," Circulation: Cardiovascular Genetics, vol. 6, no. 3, pp. 255-263, 2013. 
[12] F. Bahrehmand, A. Vaisi-Raygani, A. Kiani et al., "Matrix metalloproteinase-2 functional promoter polymorphism G1575A is associated with elevated circulatory MMP-2 levels and increased risk of cardiovascular disease in systemic lupus erythematosus patients," Lupus, vol. 21, no. 6, pp. 616-624, 2012.

[13] M. Bicakcigil, D. A. Tasan, N. Tasdelen, N. Mutlu, and S. Yavuz, "Role of fibrinolytic parameters and plasminogen activator inhibitor 1 (PAI-1) promoter polymorphism on premature atherosclerosis in SLE patients," Lupus, vol. 20, no. 10, pp. 10631071, 2011.

[14] L. N. Troelsen, P. Garred, B. Christiansen, C. Torp-Pedersen, and S. Jacobsen, "Genetically determined serum levels of mannose-binding lectin correlate negatively with common carotid intima-media thickness in systemic lupus erythematosus," Journal of Rheumatology, vol. 37, no. 9, pp. 1815-1821, 2010.

[15] B. Marasini, M. Massarotti, M. de Monti, M. Erario, G. Ghilardi, and M. L. Biondi, "Genetic contribution to carotid vascular disease in patients with systemic lupus erythematosus," Journal of Clinical Immunology, vol. 28, no. 2, pp. 131-133, 2008.

[16] A. J. Szalai, G. S. Alarcón, J. Calvo-Alén et al., "Systemic lupus erythematosus in a multiethnic US cohort (LUMINA). XXX: association between C-reactive protein (CRP) gene polymorphisms and vascular events," Rheumatology, vol. 44, no. 7, pp. 864-868, 2005.

[17] A. Mak, D. A. Isenberg, and C. S. Lau, "Global trends, potential mechanisms and early detection of organ damage in SLE," Nature Reviews Rheumatology, vol. 9, no. 5, pp. 301-310, 2013.

[18] A. H. Kao, A. Lertratanakul, J. R. Elliott et al., "Relation of carotid intima-media thickness and plaque with incident cardiovascular events in women with systemic lupus erythematosus," The American Journal of Cardiology, vol. 112, no. 7, pp. 1025-1032, 2013.

[19] A. N. Kiani, W. S. Post, L. S. Magder, and M. Petri, "Predictors of progression in atherosclerosis over 2 years in systemic lupus erythematosus," Rheumatology, vol. 50, no. 11, pp. 2071-2079, 2011.

[20] P. N. Tyrrell, J. Beyene, B. M. Feldman, B. W. McCrindle, E. D. Silverman, and T. J. Bradley, "Rheumatic disease and carotid intima-media thickness: a systematic review and meta-analysis," Arteriosclerosis, Thrombosis, and Vascular Biology, vol. 30, no. 5, pp. 1014-1026, 2010.

[21] M. A. Petri, A. N. Kiani, W. Post, L. Christopher-Stine, and L. S. Magder, "Lupus atherosclerosis prevention study (LAPS)," Annals of the Rheumatic Diseases, vol. 70, no. 5, pp. 760-765, 2011.

[22] W. Plazak, M. Pasowicz, M. Kostkiewicz et al., "Influence of chronic inflammation and autoimmunity on coronary calcifications and myocardial perfusion defects in systemic lupus erythematosus patients," Inflammation Research, vol. 60, no. 10, pp. 973-980, 2011.

[23] J. M. Von Feldt, E. R. Eisner, and A. Sawaires, "Coronary electron beam computed tomography in 13 patients with systemic lupus erythematosus and two or more cardiovascular risk factors," Journal of Clinical Rheumatology, vol. 8, no. 6, pp. 316-321, 2002.

[24] K. H. Yiu, A. A. Schouffoer, N. A. Marsan et al., "Left ventricular dysfunction assessed by speckle-tracking strain analysis in patients with systemic sclerosis: relationship to functional capacity and ventricular arrhythmias," Arthritis and Rheumatism, vol. 63, no. 12, pp. 3969-3978, 2011.

[25] K. H. Yiu, H. F. Tse, M. Y. Mok, and C. S. Lau, "Ethnic differences in cardiovascular risk in rheumatic disease: focus on Asians," Nature Reviews Rheumatology, vol. 7, no. 10, pp. 609-618, 2011.
[26] C. S. Lau and T. Cheung, "Should clinicians start measuring flow mediated dilation response in patients with systemic lupus erythematosus?" Journal of Rheumatology, vol. 38, no. 7, pp. 1231-1233, 2011.

[27] J. Aizer, E. W. Karlson, L. B. Chibnik et al., "A controlled comparison of brachial artery flow mediated dilation (FMD) and digital pulse amplitude tonometry (PAT) in the assessment of endothelial function in systemic lupus erythematosus," Lupus, vol. 18, no. 3, pp. 235-242, 2009.

[28] E. Kiss, P. Soltesz, H. Der et al., "Reduced flow-mediated vasodilation as a marker for cardiovascular complications in lupus patients," Journal of Autoimmunity, vol. 27, no. 4, pp. 211-217, 2006.

[29] S. R. Johnson, P. J. Harvey, J. S. Floras et al., "Impaired brachial artery endothelium dependent flow mediated dilation in systemic lupus erythematosus: preliminary observations," Lupus, vol. 13, no. 8, pp. 590-593, 2004.

[30] M. El-Magadmi, H. Bodill, Y. Ahmad et al., "Systemic lupus erythematosus: an independent risk factor for endothelial dysfunction in women," Circulation, vol. 110, no. 4, pp. 399-404, 2004.

[31] T. Inoue, H. Matsuoka, Y. Higashi et al., "Flow-mediated vasodilation as a diagnostic modality for vascular failure," Hypertension Research, vol. 31, no. 12, pp. 2105-2113, 2008.

[32] H. Drexler and B. Hornig, "Endothelial dysfunction in human disease," Journal of Molecular and Cellular Cardiology, vol. 31, no. 1, pp. 51-60, 1999.

[33] G. M. Rubanyi, "The role of endothelium in cardiovascular homeostasis and diseases," Journal of Cardiovascular Pharmacology, vol. 22, supplement 4, pp. S1-S14, 1993.

[34] V. Bauer and R. Sotníková, "Nitric oxide-the endotheliumderived relaxing factor and its role in endothelial functions," General Physiology and Biophysics, vol. 29, no. 4, pp. 319-340, 2010.

[35] H. Lei, S. Luo, H. Qin, and Y. Xia, "Molecular mechanisms of endothelial NO synthase uncoupling," Current Pharmaceutical Design, 2013.

[36] T. J. Anderson, M. D. Gerhard, I. T. Meredith et al., "Systemic nature of endothelial dysfunction in atherosclerosis," The American Journal of Cardiology, vol. 75, no. 6, pp. 71B-74B, 1995.

[37] J. P. J. Halcox, W. H. Schenke, G. Zalos et al., "Prognostic value of coronary vascular endothelial dysfunction," Circulation, vol. 106, no. 6, pp. 653-658, 2002.

[38] R. de Caterina, P. Libby, H. B. Peng et al., "Nitric oxide decreases cytokine-induced endothelial activation. Nitric oxide selectively reduces endothelial expression of adhesion molecules and proinflammatory cytokines," Journal of Clinical Investigation, vol. 96, no. 1, pp. 60-68, 1995.

[39] A. Blum and H. Miller, "The effects of L-arginine on atherosclerosis and heart disease," International Journal of Cardiovascular Interventions, vol. 2, no. 2, pp. 97-100, 1999.

[40] M. Ewart, C. F. Kohlhaas, and I. P. Salt, "Inhibition of tumor necrosis factor $\alpha$-stimulated monocyte adhesion to human aortic endothelial cells by AMP-activated protein kinase," Arteriosclerosis, Thrombosis, and Vascular Biology, vol. 28, no. 12, pp. 2255-2257, 2008.

[41] C. Moore, D. Sanz-Rosa, and M. Emerson, "Distinct role and location of the endothelial isoform of nitric oxide synthase in regulating platelet aggregation in males and females in vivo," European Journal of Pharmacology, vol. 651, no. 1-3, pp. 152-158, 2011. 
[42] D. S. N. Lima, E. I. Sato, V. C. Lima, F. Miranda Jr., and F. H. Hatta, "Brachial endothelial function is impaired in patients with systemic lupus erythematosus," Journal of Rheumatology, vol. 29, no. 2, pp. 292-297, 2002.

[43] A. Mak, Y. Liu, and R. C. Ho, "Endothelium-dependent but not endothelium-independent flow-mediated dilation is significantly reduced in patients with systemic lupus erythematosus without vascular events: a metaanalysis and metaregression," Journal of Rheumatology, vol. 38, no. 7, pp. 1296-1303, 2011.

[44] X. Liu, G. X. Zhang, X. Y. Zhang et al., "Lacidipine improves endothelial repair capacity of endothelial progenitor cells from patients with essential hypertension," International Journal of Cardiology, vol. 168, no. 4, pp. 3317-3326, 2013.

[45] J. H. Moon, M. K. Chae, K. J. Kim et al., "Decreased endothelial progenitor cells and increased serum glycated albumin are independently correlated with plaque-forming carotid artery atherosclerosis in type 2 diabetes patients without documented ischemic disease," Circulation Journal, vol. 76, no. 9, pp. 22732279, 2012.

[46] R. Suzuki, N. Fukuda, M. Katakawa et al., "Effects of an angiotensin II receptor blocker on the impaired function of endothelial progenitor cells in patients with essential hypertension," The American Journal of Hypertension, 2013.

[47] C. Urbich and S. Dimmeler, "Risk factors for coronary artery disease, circulating endothelial progenitor cells, and the role of HMG-CoA reductase inhibitors," Kidney International, vol. 67, no. 5, pp. 1672-1676, 2005.

[48] N. W. Tsai, S. H. Hung, C. R. Huang et al., "The association between circulating endothelial progenitor cells and outcome in different subtypes of acute ischemic stroke," Clinica Chimica Acta, vol. 427, pp. 6-10, 2014.

[49] N. Werner, S. Kosiol, T. Schiegl et al., "Circulating endothelial progenitor cells and cardiovascular outcomes," The New England Journal of Medicine, vol. 353, no. 10, pp. 999-1007, 2005.

[50] M. Y. Mok, K. H. Yiu, C. Y. Wong et al., "Low circulating level of CD133+KDR+cells in patients with systemic sclerosis," Clinical and Experimental Rheumatology, vol. 28, no. 5, supplement 62, pp. S19-S25, 2010.

[51] M. Kuwana and Y. Okazaki, "Quantification of circulating endothelial progenitor cells in systemic sclerosis: a direct comparison of protocols," Annals of the Rheumatic Diseases, vol. 71, no. 4, pp. 617-620, 2012.

[52] R. Castejon, C. Jimenez-Ortiz, S. Valero-Gonzalez, S. Rosado, S. Mellor, and M. Yebra-Bango, "Decreased circulating endothelial progenitor cells as an early risk factor of subclinical atherosclerosis in systemic lupus erythematosus," Rheumatology, 2013.

[53] J. Rodríguez-Carrio, C. Prado, B. de Paz et al., "Circulating endothelial cells and their progenitors in systemic lupus erythematosus and early rheumatoid arthritis patients," Rheumatology, vol. 51, no. 10, pp. 1775-1784, 2012.

[54] J. R. A. J. Moonen, K. de Leeuw, X. J. G. Y. van Seijen et al., "Reduced number and impaired function of circulating progenitor cells in patients with systemic lupus erythematosus," Arthritis Research and Therapy, vol. 9, no. 4, article R84, 2007.

[55] M. J. Kaplan, "Premature vascular damage in systemic lupus erythematosus," Autoimmunity, vol. 42, no. 7, pp. 580-586, 2009.

[56] J. J. Hooks, H. M. Moutsopoulos, S. A. Geis, N. I. Stahl, J. L. Decker, and A. L. Notkins, "Immune interferon in the circulation of patients with autoimmune disease," The New England Journal of Medicine, vol. 301, no. 1, pp. 5-8, 1979.

[57] A. M. Yee, Y. K. Yip, H. D. Fischer, and J. P. Buyon, "Serum activity that confers acid lability to $\alpha$-interferon in systemic lupus erythematosus: its association with disease activity and its independence from circulating $\alpha$-interferon," Arthritis and Rheumatism, vol. 33, no. 4, pp. 563-568, 1990.

[58] V. Rus, V. Zernetkina, R. Puliaev, C. Cudrici, S. Mathai, and C. $\mathrm{S}$. Via, "Increased expression and release of functional tumor necrosis factor-related apoptosis-inducing ligand (TRAIL) by T cells from lupus patients with active disease," Clinical Immunology, vol. 117, no. 1, pp. 48-56, 2005.

[59] P. Secchiero, E. Rimondi, M. G. di Iasio et al., "C-Reactive protein downregulates TRAIL expression in human peripheral monocytes via an Egr-1-dependent pathway," Clinical Cancer Research, vol. 19, no. 8, pp. 1949-1959, 2013.

[60] B. A. Di Bartolo, S. P. Cartland, H. H. Harith, Y. V. Bobryshev, M. Schoppet, and M. M. Kavurma, "TRAIL-deficiency accelerates vascular calcification in atherosclerosis via modulation of RANKL," PLoS ONE, vol. 8, no. 9, Article ID e74211, 2013.

[61] A. Niessner and C. M. Weyand, "Dendritic cells in atherosclerotic disease," Clinical Immunology, vol. 134, no. 1, pp. 25-32, 2010.

[62] M. Higashiyama, R. Hokari, C. Kurihara et al., "Interferon- $\alpha$ increases monocyte migration via platelet-monocyte interaction in murine intestinal microvessels," Clinical and Experimental Immunology, vol. 162, no. 1, pp. 156-162, 2010.

[63] P. Duffau, J. Seneschal, C. Nicco et al., "Platelet CD154 potentiates interferon- $\alpha$ secretion by plasmacytoid dendritic cells in systemic lupus erythematosus," Science Translational Medicine, vol. 2, no. 47, Article ID 47ra63, 2010.

[64] S. G. Thacker, C. C. Berthier, D. Mattinzoli, M. P. Rastaldi, M. Kretzler, and M. J. Kaplan, "The detrimental effects of IFN- $\alpha$ on vasculogenesis in lupus are mediated by repression of IL1 pathways: potential role in atherogenesis and renal vascular rarefaction," Journal of Immunology, vol. 185, no. 7, pp. 44574469, 2010.

[65] W. Koenig, M. Karakas, A. Zierer et al., "Oxidized LDL and the risk of coronary heart disease: results from the MONICA/ KORA Augsburg study," Clinical Chemistry, vol. 57, no. 8, pp. 1196-1200, 2011.

[66] S. Tsimikas, E. S. Brilakis, E. R. Miller et al., "Oxidized phospholipids, Lp(a) lipoprotein, and coronary artery disease," The New England Journal of Medicine, vol. 353, no. 1, pp. 46-57, 2005.

[67] E. Svenungsson, K. Jensen-Urstad, M. Heimbürger et al., "Risk factors for cardiovascular disease in systemic lupus erythematosus," Circulation, vol. 104, no. 16, pp. 1887-1893, 2001.

[68] J. Frostegård, E. Svenungsson, R. Wu et al., "Lipid peroxidation is enhanced in patients with systemic lupus erythematosus and is associated with arterial and renal disease manifestations," Arthritis and Rheumatism, vol. 52, no. 1, pp. 192-200, 2005.

[69] D. Lopez, I. Garcia-Valladares, C. A. Palafox-Sanchez et al., "Oxidized low-density lipoprotein/ $\beta 2$-glycoprotein I complexes and autoantibodies to oxLig-1/ $\beta 2$-glycoprotein I in patients with systemic lupns erythematosus and antiphospholipid syndrome," The American Journal of Clinical Pathology, vol. 121, no. 3, pp. 426-436, 2004.

[70] B. J. Hunt, "The endothelium in atherogenesis," Lupus, vol. 9, no. 3, pp. 189-193, 2000.

[71] G. K. Hansson, "Mechanisms of disease: inflammation, atherosclerosis, and coronary artery disease," The New England Journal of Medicine, vol. 352, no. 16, pp. 1685-1695, 2005.

[72] A. Tsouknos, G. B. Nash, and G. E. Rainger, "Monocytes initiate a cycle of leukocyte recruitment when cocultured with endothelial cells," Atherosclerosis, vol. 170, no. 1, pp. 49-58, 2003. 
[73] K. J. Moore and I. Tabas, "Macrophages in the pathogenesis of atherosclerosis," Cell, vol. 145, no. 3, pp. 341-355, 2011.

[74] Y. Huang, Z. Wu, M. Riwanto et al., "Myeloperoxidase, paraoxonase-1, and HDL form a functional ternary complex," Journal of Clinical Investigation, vol. 123, no. 9, pp. 3815-3828, 2013.

[75] M. McMahon, J. Grossman, J. FitzGerald et al., "Proinflammatory high-density lipoprotein as a biomarker for atherosclerosis in patients with systemic lupus erythematosus and rheumatoid arthritis," Arthritis and Rheumatism, vol. 54, no. 8, pp. 25412549,2006

[76] G. Wiesner, M. Vaz, G. Collier et al., "Leptin is released from the human brain: influence of adiposity and gender," Journal of Clinical Endocrinology and Metabolism, vol. 84, no. 7, pp. 22702274, 1999.

[77] A. M. Wallace, A. D. McMahon, C. J. Packard et al., "Plasma leptin and the risk of cardiovascular disease in the West of Scotland coronary prevention study (WOSCOPS)," Circulation, vol. 104, no. 25, pp. 3052-3056, 2001.

[78] G. A. Payne, J. D. Tune, and J. D. Knudson, "Leptin-induced endothelial dysfunction: a target for therapeutic interventions," Current Pharmaceutical Design, vol. 20, no. 4, pp. 603-608, 2014.

[79] M. McMahon, B. J. Skaggs, J. M. Grossman et al., "A panel of biomarkers is associated with increased risk of the presence and progression of atherosclerosis in women with systemic lupus erythematosus," Arthritis and Rheumatology, vol. 66, no. 1, pp. 130-139, 2014.

[80] M. McMahon, B. J. Skaggs, L. Sahakian et al., "High plasma leptin levels confer increased risk of atherosclerosis in women with systemic lupus erythematosus, and are associated with inflammatory oxidised lipids," Annals of the Rheumatic Diseases, vol. 70, no. 9, pp. 1619-1624, 2011.

[81] G. Amarilyo, N. Iikuni, F. D. Shi, A. Liu, G. Matarese, and A. la Cava, "Leptin promotes lupus T-cell autoimmunity," Clinical Immunology, vol. 149, no. 3, pp. 530-533, 2013.

[82] Y. Yu, Y. Liu, F. D. Shi, H. Zou, G. Matarese, and A. la Cava, "Cutting edge: leptin-induced ROR $\gamma$ t expression in CD4+ T cells promotes Th17 responses in systemic lupus erythematosus," Journal of Immunology, vol. 190, no. 7, pp. 3054-3058, 2013.

[83] N. R. Madamanchi, A. Vendrov, and M. S. Runge, "Oxidative stress and vascular disease," Arteriosclerosis, Thrombosis, and Vascular Biology, vol. 25, no. 1, pp. 29-38, 2005.

[84] A. Mak, Z. A. Almsherq, Y. W. Lai, A. A. Cheak, and Y. Deng, "Intracellular tubulo-reticular structures of peripheral blood mononuclear cells as an ultra-structural marker of disease activity in systemic lupus erythematosus: a pilot study," International Journal of Rheumatic Diseases, vol. 16, no. 6, pp. 692-697, 2013.

[85] S. Z. Hassan, T. A. Gheita, S. A. Kenawy, A. T. Fahim, I. M. ElSorougy, and M. S. Abdou, "Oxidative stress in systemic lupus erythematosus and rheumatoid arthritis patients: relationship to disease manifestations and activity," International Journal of Rheumatic Diseases, vol. 14, no. 4, pp. 325-331, 2011.

[86] G. Wang, S. S. Pierangeli, E. Papalardo, G. A. S. Ansari, and M. F. Khan, "Markers of oxidative and nitrosative stress in systemic lupus erythematosus: correlation with disease activity," Arthritis and Rheumatism, vol. 62, no. 7, pp. 2064-2072, 2010.

[87] W. N. Huang, T. K. Tso, and H. Y. Huang, "Enhanced oxidative status but not corresponding elevated antioxidative status by anticardiolipin antibody and disease activity in patients with systemic lupus erythematosus," Rheumatology International, vol. 27, no. 5, pp. 453-458, 2007.
[88] D. S. Vinay and B. S. Kwon, "4-1BB signaling beyond T cells," Cellular and Molecular Immunology, vol. 8, no. 4, pp. 281-284, 2011.

[89] C. Wang, G. H. Y. Lin, A. J. McPherson, and T. H. Watts, "Immune regulation by 4-1BB and 4-1BBL: complexities and challenges," Immunological Reviews, vol. 229, no. 1, pp. 192-215, 2009.

[90] Y. Sun, H. M. Chen, S. K. Subudhi et al., "Costimulatory molecule-targeted antibody therapy of a spontaneous autoimmune disease," Nature Medicine, vol. 8, no. 12, pp. 1405-1413, 2002.

[91] J. Foell, S. Strahotin, S. P. O’Neil et al., “CD137 costimulatory T cell receptor engagement reverses acute disease in lupus-prone NZB $\times$ NZW F1 mice," Journal of Clinical Investigation, vol. 111, no. 10, pp. 1505-1518, 2003.

[92] B. Z. Quek, Y. C. Lim, J. H. R. Lin et al., "CD137 enhances monocyte-ICAM-1 interactions in an E-selectin-dependent manner under flow conditions," Molecular Immunology, vol. 47, no. 9, pp. 1839-1847, 2010.

[93] D. Drenkard, F. M. Becke, J. Langstein et al., “CD137 is expressed on blood vessel walls at sites of inflammation and enhances monocyte migratory activity," FASEB Journal, vol. 21, no. 2, pp. 456-463, 2007.

[94] P. S. Olofsson, L. Å. Söderström, D. Wågsäter et al., “CD137 is expressed in human atherosclerosis and promotes development of plaque inflammation in hypercholesterolemic mice," Circulation, vol. 117, no. 10, pp. 1292-1301, 2008.

[95] Q. Lu, A. Wu, L. Tesmer, D. Ray, N. Yousif, and B. Richardson, "Demethylation of CD40LG on the inactive X in T cells from women with lupus," Journal of Immunology, vol. 179, no. 9, pp. 6352-6358, 2007.

[96] Y. Zhou, J. Yuan, Y. Pan et al., “T cell CD40LG gene expression and the production of IgG by autologous B cells in systemic lupus erythematosus," Clinical Immunology, vol. 132, no. 3, pp. 362-370, 2009.

[97] M. J. Yellin and U. Thienel, "T cells in the pathogenesis of systemic lupus erythematosus: potential roles of CD154-CD40 interactions and costimulatory molecules," Current Rheumatology Reports, vol. 2, no. 1, pp. 24-31, 2000.

[98] F. Mach, U. Schönbeck, G. K. Sukhova, E. Atkinson, and P. Libby, "Reduction of atherosclerosis in mice by inhibition of CD40 signalling," Nature, vol. 394, no. 6689, pp. 200-203, 1998.

[99] D. T. Boumpas, R. Furie, S. Manzi et al., "A short course of BG9588 (anti-CD40 ligand antibody) improves serologic activity and decreases hematuria in patients with proliferative lupus glomerulonephritis," Arthritis and Rheumatism, vol. 48, no. 3, pp. 719-727, 2003.

[100] J. Yang, Y. Chu, X. Yang et al., “Th17 and natural treg cell population dynamics in systemic lupus erythematosus," Arthritis and Rheumatism, vol. 60, no. 5, pp. 1472-1483, 2009.

[101] T. van Es, G. H. M. van Puijvelde, O. H. Ramos et al., "Attenuated atherosclerosis upon IL-17R signaling disruption in LDLr deficient mice," Biochemical and Biophysical Research Communications, vol. 388, no. 2, pp. 261-265, 2009.

[102] S. Chen, T. R. Crother, and M. Arditi, "Emerging role of IL-17 in atherosclerosis," Journal of Innate Immunity, vol. 2, no. 4, pp. 325-333, 2010.

[103] A. Mak, C. S. Tang, and R. C. Ho, "Serum tumour necrosis factor- $\alpha$ is associated with poor health-related quality of life and depressive symptoms in patients with systemic lupus erythematosus," Lupus, vol. 22, no. 3, pp. 254-261, 2013. 
[104] Y. H. Rho, C. P. Chung, A. Oeser et al., "Novel cardiovascular risk factors in premature coronary atherosclerosis associated with systemic lupus erythematosus," Journal of Rheumatology, vol. 35, no. 9, pp. 1789-1794, 2008.

[105] J. F. McHale, O. A. Harari, D. Marshall, and D. O. Haskard, "TNF- $\alpha$ and IL-1 sequentially induce endothelial ICAM-1 and VCAM-1 expression in MRL/lpr lupus-prone mice," Journal of Immunology, vol. 163, no. 7, pp. 3993-4000, 1999.

[106] A. Schiopu, J. Bengtsson, I. Söderberg et al., "Recombinant human antibodies against aldehyde-modified apolipoprotein B100 peptide sequences inhibit atherosclerosis," Circulation, vol. 110, no. 14, pp. 2047-2052, 2004.

[107] W. Palinski, E. Miller, and J. L. Witztum, "Immunization of low density lipoprotein (LDL) receptor-deficient rabbits with homologous malondialdehyde-modified LDL reduces atherogenesis," Proceedings of the National Academy of Sciences of the United States of America, vol. 92, no. 3, pp. 821-825, 1995.

[108] F. I. Romero, O. Amengual, T. Atsumi, M. A. Khamashta, F. J. Tinahones, and G. R. V. Hughes, "Arterial disease in lupus and secondary antiphospholipid syndrome: association with anti$\beta 2$-glycoprotein I antibodies but not with antibodies against oxidized low-density lipoprotein," The British Journal of Rheumatology, vol. 37, no. 8, pp. 883-888, 1998.

[109] G. Hayem, P. Nicaise-Roland, E. Palazzo et al., "Anti-oxidized low-density-lipoprotein (OxLDL) antibodies in systemic lupus erythematosus with and without antiphospholipid syndrome," Lupus, vol. 10, no. 5, pp. 346-351, 2001.

[110] J. George, D. Harats, B. Gilburd et al., "Immunolocalization of $\beta 2$-glycoprotein I (apolipoprotein $\mathrm{H}$ ) to human atherosclerotic plaques: potential implications for lesion progression," Circulation, vol. 99, no. 17, pp. 2227-2230, 1999.

[111] P. Valer, B. Paul, B. Eugenia, and B. Camelia, "Annexin A5 as independent predictive biomarker for subclinical atherosclerosis and endothelial dysfunction in systemic lupus erythematosus patients," Clinical Laboratory, vol. 59, no. 3-4, pp. 359-367, 2013.

[112] C. Ravanat, G. Archipoff, A. Beretz, A. Freund, J. P. Cazenve, and J. M. Freyssinet, "Use of annexin-V to demonstrate the role of phosphatidylserine exposure in the maintenance of haemostatic balance by endothelial cells," Biochemical Journal, vol. 282, part 1, pp. 7-13, 1992.

[113] A. Hrycek and P. Cieślik, "Annexin A5 and anti-annexin antibodies in patients with systemic lupus erythematosus," Rheumatology International, vol. 32, no. 5, pp. 1335-1342, 2012.

[114] J. H. Rand, X. X. Wu, H. A. M. Andree et al., "Antiphospholipid antibodies accelerate plasma coagulation by inhibiting annexin-V binding to phospholipids: a "lupus procoagulant" phenomenon," Blood, vol. 92, no. 5, pp. 1652-1660, 1998.

[115] R. M. Clancy, "Circulating endothelial cells and vascular injury in systemic lupus erythematosus," Current Rheumatology Reports, vol. 2, no. 1, pp. 39-43, 2000.

[116] D. A. Fraser and A. J. Tenner, "Innate immune proteins Clq and mannan-binding lectin enhance clearance of atherogenic lipoproteins by human monocytes and macrophages," Journal of Immunology, vol. 185, no. 7, pp. 3932-3939, 2010.

[117] V. Brinkmann, U. Reichard, C. Goosmann et al., "Neutrophil extracellular traps kill bacteria," Science, vol. 303, no. 5663, pp. 1532-1535, 2004.

[118] G. S. Garcia-Romo, S. Caielli, B. Vega et al., "Netting neutrophils are major inducers of type I IFN production in pediatric systemic lupus erythematosus," Science Translational Medicine, vol. 3, no. 73, Article ID 73ra20, 2011.
[119] A. K. Gupta, M. B. Joshi, M. Philippova et al., "Activated endothelial cells induce neutrophil extracellular traps and are susceptible to NETosis-mediated cell death," FEBS Letters, vol. 584, no. 14, pp. 3193-3197, 2010.

[120] R. Lande, D. Ganguly, V. Facchinetti et al., "Neutrophils activate plasmacytoid dendritic cells by releasing self-DNA-peptide complexes in systemic lupus erythematosus," Science Translational Medicine, vol. 3, no. 73, Article ID 73ra19, 2011.

[121] J. Yamaoka, K. Kabashima, M. Kawanishi, K. Toda, and Y. Miyachi, "Cytotoxicity of IFN- $\gamma$ and TNF- $\alpha$ for vascular endothelial cell is mediated by nitric oxide," Biochemical and Biophysical Research Communications, vol. 291, no. 4, pp. 780-786, 2002.

[122] M. F. Denny, S. Thacker, H. Mehta et al., "Interferon- $\alpha$ promotes abnormal vasculogenesis in lupus: a potential pathway for premature atherosclerosis," Blood, vol. 110, no. 8, pp. 2907-2915, 2007.

[123] J. M. Kahlenberg, S. G. Thacker, C. C. Berthier, C. D. Cohen, M. Kretzler, and M. J. Kaplan, "Inflammasome activation of IL18 results in endothelial progenitor cell dysfunction in systemic lupus erythematosus," Journal of Immunology, vol. 187, no. 11, pp. 6143-6156, 2011.

[124] J. Rodríguez-Carrio, M. Alperi-López, P. López, S. AlonsoCastro, F. J. Ballina-García, and A. Suárez, "Angiogenic T cells are decreased in rheumatoid arthritis patients," Annals of the Rheumatic Diseases, 2014.

[125] S. G. Thacker, D. Duquaine, J. Park, and M. J. Kaplan, "Lupusprone New Zealand Black/New Zealand white F1 mice display endothelial dysfunction and abnormal phenotype and function of endothelial progenitor cells," Lupus, vol. 19, no. 3, pp. 288299, 2010.

[126] M. F. Denny, S. Yalavarthi, W. Zhao et al., "A distinct subset of proinflammatory neutrophils isolated from patients with systemic lupus erythematosus induces vascular damage and synthesizes type I IFNs," Journal of Immunology, vol. 184, no. 6, pp. 3284-3297, 2010.

[127] E. C. Somers, W. Zhao, E. E. Lewis et al., “Type I interferons are associated with subclinical markers of cardiovascular disease in a cohort of systemic lupus erythematosus patients," PLoS ONE, vol. 7, no. 5, Article ID e37000, 2012. 


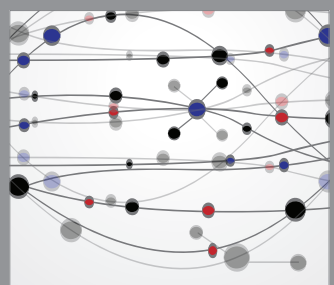

The Scientific World Journal
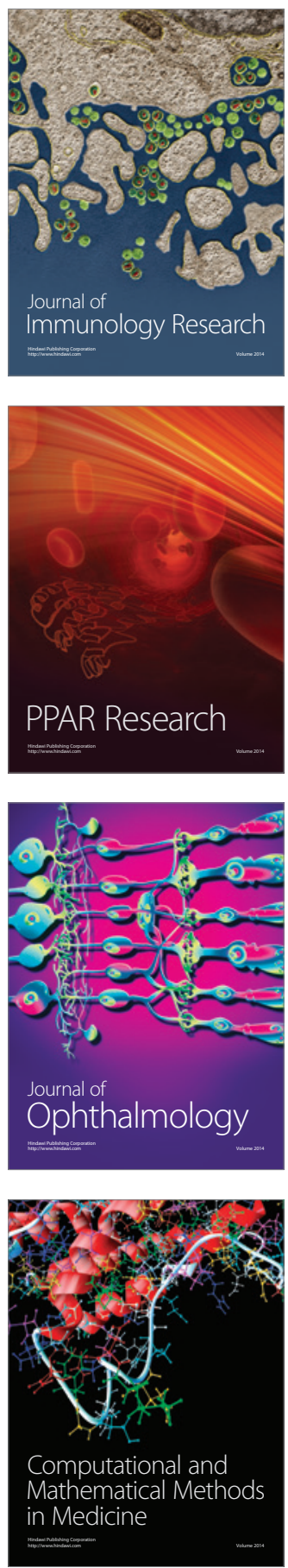

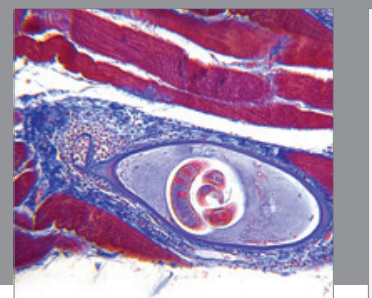

Gastroenterology

Research and Practice
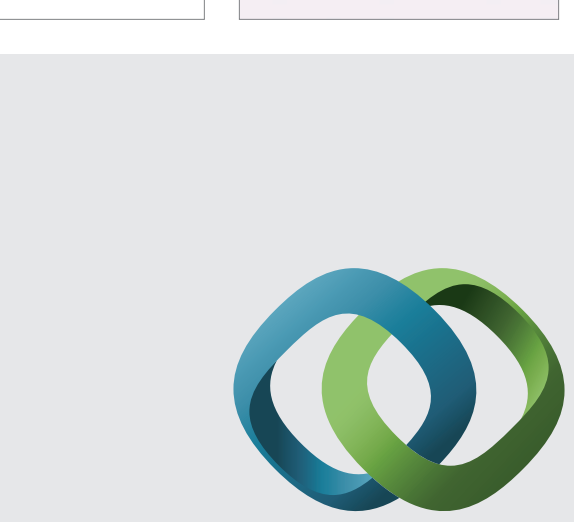

\section{Hindawi}

Submit your manuscripts at

http://www.hindawi.com
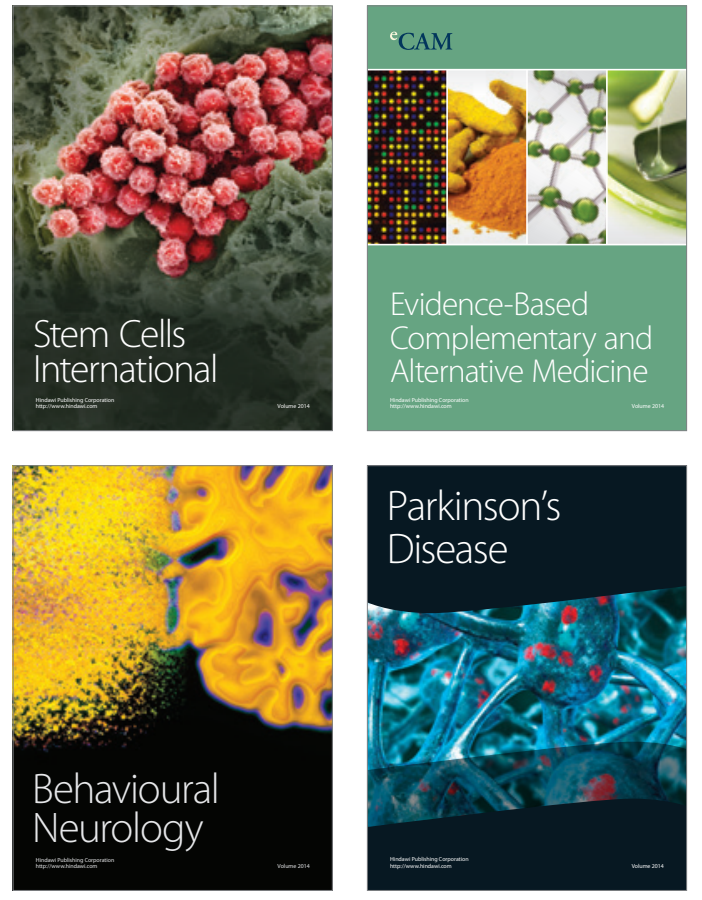
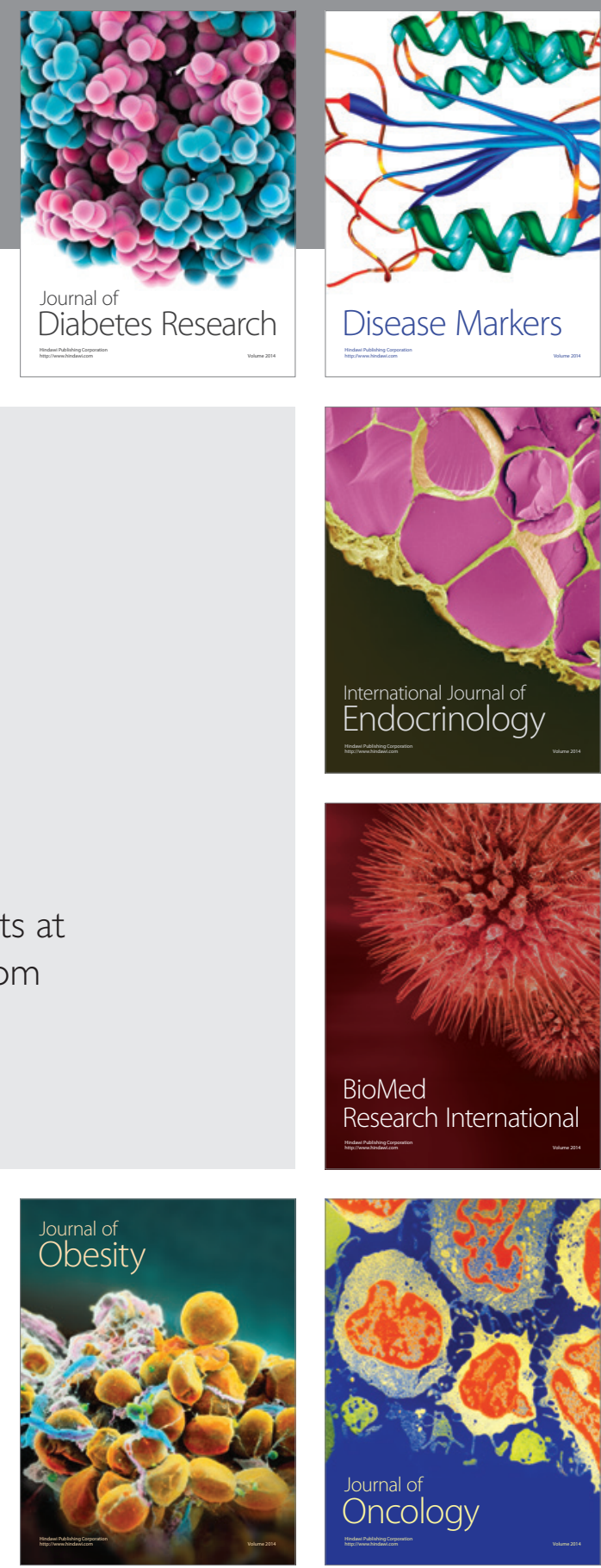

Disease Markers
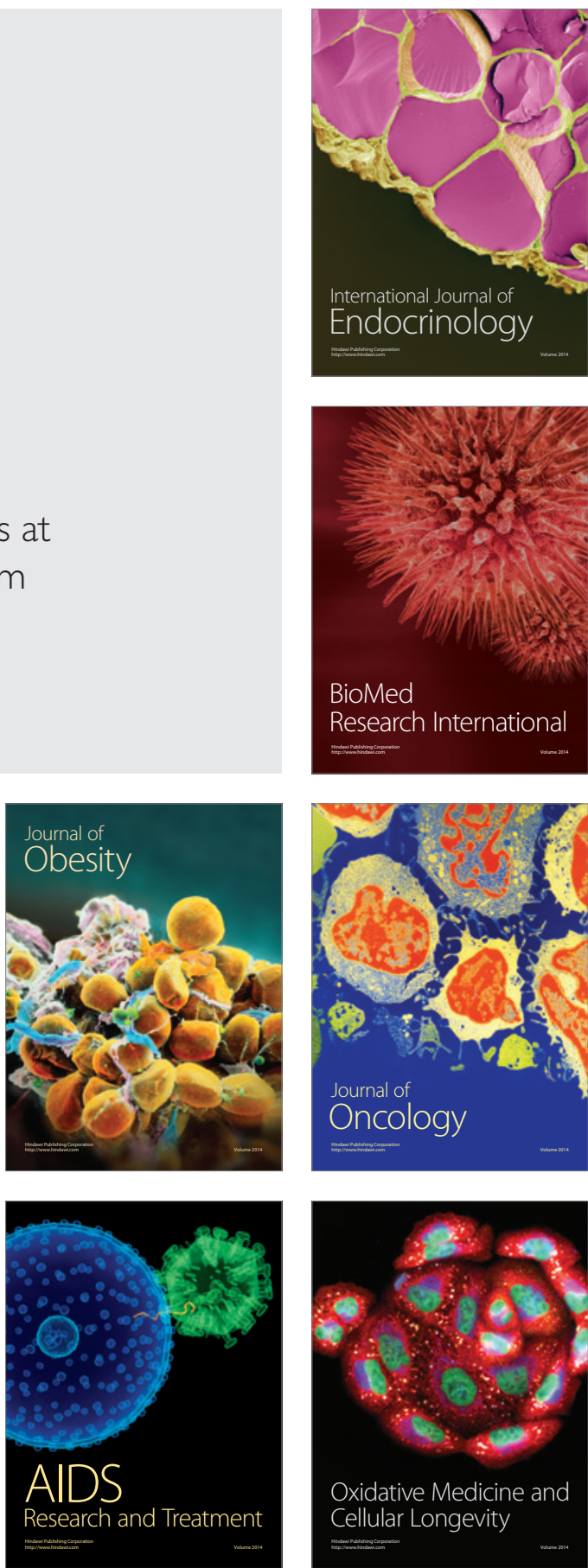